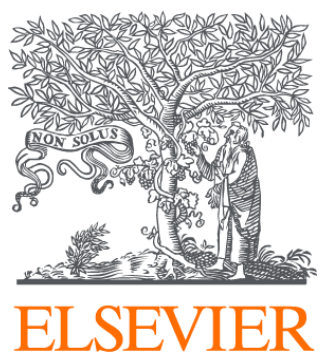

Since January 2020 Elsevier has created a COVID-19 resource centre with free information in English and Mandarin on the novel coronavirus COVID-

19. The COVID-19 resource centre is hosted on Elsevier Connect, the company's public news and information website.

Elsevier hereby grants permission to make all its COVID-19-related research that is available on the COVID-19 resource centre - including this research content - immediately available in PubMed Central and other publicly funded repositories, such as the WHO COVID database with rights for unrestricted research re-use and analyses in any form or by any means with acknowledgement of the original source. These permissions are granted for free by Elsevier for as long as the COVID-19 resource centre remains active. 
Correspondence

\section{Re: a British Society of Thoracic Imaging statement: considerations in designing local imaging diagnostic algorithms for the COVID-19 pandemic}

Sir-We read with great interest the statement from Nair and colleagues of the British Society of Thoracic Imaging (BSTI), which provides a thorough insight into the role of imaging in combating the COVID-19 pandemic; however, we noticed a potentially consequential error within the text. In answering Question 2, the authors comment that "CXR may be abnormal in the majority of COVID-19 cases", incorrectly inferring that the study of Huang et al. found "bilateral radiographic abnormalities in 40/41 (98\%) of cases". The study of Huang et al. in The Lancet does mistakenly state that they found "bilateral involvement of chest radiographs" in 40/41 patients in Table 2 of their results; however, from reading the main text, it is clear that the imaging method they are referring to is actually chest computed tomography (CT), not chest radiography (CXR): "On admission, abnormalities in chest CT images were detected among all patients. Of the 41 patients, 40 (98\%) had bilateral involvement (Table 2)". ${ }^{2}$ The mismatch between the results table and the main text in The Lancet may have contributed to this error.

In fact, it is evident from current literature that the sensitivity of CXR is limited for COVID-19. The study of Guan et al., also cited by Nair et al., reported CXR abnormalities in only $162 / 274$ (59.1\%) of COVID-19 patients. ${ }^{3}$ In addition, a more recent study by Wong et al. reported abnormal CXR in $44 / 64(68.8 \%)$ of COVID-19 patients on presentation ${ }^{4}$; however, it is important to note that both of these studies included hospitalised patients, representing individuals with more severe illness.

A recently published study from New York City presents a different picture of the sensitivity of CXR in ambulatory care. Weinstock et al. reported CXR findings of 636 COVID-19 patients presenting to urgent-care centres and found that only 168 (26.4\%) were reported originally as abnormal. ${ }^{5}$ Subsequently, they had 11 board-certified radiologists re-read these radiographs with prior knowledge of the patients' COVID-19 diagnosis. In spite of this, the panel classified only $41.7 \%$ of CXR findings as abnormal.

Therefore, in light of the above, it is possible that CXR may not be abnormal in the majority of COVID-19 cases presenting to emergency departments.

\section{Declaration of interests}

The authors declare no conflict of interest.

\section{References}

1. Nair A, Rodrigues JCL, Hare S, et al. A British Society of Thoracic Imaging statement: considerations in designing local imaging diagnostic algorithms for the COVID-19 pandemic. Clin Radiol 2020;75(5):329-34.

2. Huang C, Wang Y, Li X, et al. Clinical features of patients infected with 2019 novel coronavirus in Wuhan, China. Lancet 2020;395(10223): 497-506.

3. Guan W-J, Ni Z-Y, Hu Y-HY, et al. Clinical characteristics of coronavirus disease 2019 in China. N Engl J Med 2020;82(18):1708-20.

4. Wong HYF, Lam HYS, Fong AH-T, et al. Frequency and distribution of chest radiographic findings in COVID-19 positive patients. Radiology $2020 \mathrm{Mar}$ 27:201160.

5. Weinstock MB, Echenique ANA, Russell JW, et al. Chest X-ray findings in 636 ambulatory patients with COVID-19 presenting to an urgent care center: a normal chest X-ray is no guarantee. J Urgent Care Med 2020:13-8.

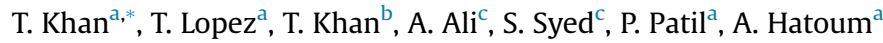
${ }^{\mathrm{a}}$ University of Cambridge, Cambridge, UK

${ }^{\mathrm{b}}$ University Hospitals Plymouth NHS Trust, Derriford Hospital, Plymouth, UK

${ }^{\mathrm{c}}$ Basildon and Thurrock University Hospital NHS Foundation Trust, Basildon Hospital, Basildon, UK

* Guarantor and correspondent: T. Khan, University of Cambridge, Cambridge, UK E-mail address: tsk29@cam.ac.uk (T. Khan)

\section{https://doi.org/10.1016/j.crad.2020.05.009}

(c) 2020 The Royal College of Radiologists. Published by Elsevier Ltd. All rights reserved. 